\title{
Effects of Pipe Wall Offsets on Differential Pressure Meter Accuracy
}

\author{
JESSE M. POPE, ${ }^{1}$ STEVEN L. BARFUSS, ${ }^{2}$ MICHAEL C. JOHNSON, ${ }^{2}$ \\ AND ZACHARY B. SHARP3
}

\author{
${ }^{1}$ Gannett Fleming Inc., Camp Hill, Pa. \\ ${ }^{2}$ Utah State University, Logan \\ ${ }^{3}$ Utah Water Research Laboratory, Logan
}

\begin{abstract}
Accurate flow measurement is essential for the management of any type of fluid system. This research investigated the effect on accuracy that five types of 12-in. differential-pressure flow meters have as a result of being installed in pipelines of differing inside diameter. The types of meters chosen for this research were the classical Venturi meter, Halmi Venturi Tube, wedge meter, V-cone meter, and the X-meter. Each meter was tested for accuracy with

10 pipe wall offsets varying from a 0.125 -in. sudden contraction to a 0.937 -in. sudden expansion of the pipe radius. The meters' reading during each test series was compared with the meters' reading with no pipe wall offset at the same Reynolds number. This research demonstrated that for accurate flow measurement, most flow meters require that the inside diameter of the piping be the same as the inside diameter of the meter.
\end{abstract}

Keywords: differential pressure meters, installation effects, water meter testing

In closed conduits, many methods and meter types are available to measure the flow. Laboratory flow-meter calibrations provide a means for accurately determining the discharge characteristics of the flow meter in any piping configuration into which the meter may be installed. To provide laboratory conditions that are repeatable and expected, the flow profile approaching the meter needs to be uniform (i.e., the flow must be fully developed and the streamlines parallel in full pipe flow).

Flow conditions are affected by various pipe fittings such as elbows, valves, and sudden changes in pipe diameter, to name a few. These disturbances, if placed immediately upstream of a meter, may cause irregular flow conditions within the meter, which may cause it to produce incorrect measurements. Several laboratory experiments have been conducted on installation effects for several types of differential pressure (DP) meters. For example, Rapier (1981) concluded that a short section of reduced-diameter pipe installed 25 diameters upstream of the meter slightly affects a Venturi nozzle's accuracy. Also, the V-cone meter had minimal effects with pipe elbows installed immediately upstream of the meter (Ifft \& Mikkelsen 1993). However, the authors have been unable to find any data to show how a meter is affected by a sudden change in pipe diameter at the meter inlet. When the inside diameter of the upstream pipe differs from the inside diameter of the meter itself, meter accuracy may be affected. This type of scenario may occur if a meter was installed in a pipeline that did not match the inside diameter, or a biofilm layer may exist on a pipe wall that would not exist on a meter wall of a new replacement meter. In short, the inside diameter of the pipe into which a flow meter is installed should always be considered.

Flow meters are usually constructed on the basis of the pressure rating of the pipe in which the meters will be installed. A pipe that has a higher pressure rating will have a thicker pipe wall. If for any reason the meter is incorrectly installed or has a different inside inlet diameter from the pipeline, the fluid will encounter a sudden increase or decrease in pipe diameter. As fluid flows across this sudden change in diameter, streamlines can separate from the pipe wall, causing a less-than-ideal condition as the fluid moves through the meter.

\section{PIPE SIZING}

The original system established to designate pipe dimensions was known as iron pipe size (IPS). Under this system, the pipe size was based on the approximate inside diameter. All pipe sizes had the same pipe wall thickness, which became known as standard (STD). Eventually, industries required pipe that could withstand higher pressures. To accommodate this new requirement, two additional pipe wall thicknesses were manufactured in 1927. One was called extra strong (XS) or extra heavy (XH), and the other was called double extra strong (XXS) or double extra heavy (XXH). The outside pipe diameter remained unchanged while the inside diameter decreased as a result of the increased pipe wall thickness.

In 1927, the American Standards Association replaced IPS with nominal pipe size (NPS), and many pipe wall thicknesses were made available. NPS is a dimensionless indicator of the size of the 
pipe based on the outside pipe diameter without an inch symbol. Note that for pipe sizes greater than 12 in., the NPS specifies the pipe's outside diameter exactly. For sizes less than 14 in., the NPS specifies the inside diameter for the standard pipe wall thickness. The pipe schedules available in NPS for carbon steel pipe in each pipe size are 5, 10, 20, 30, STD, 40, 60, 80 S (also known as XH), 80, 100, 120, 140, 160, and XXH (Nayyar 2000).

\section{OBJECTIVE}

DP meters are among the most common types of flow meters in closed conduits and have been used worldwide for over 100 years. The main objective of this research was to quantify the extent of the effects that various types of standard-schedule, differential-producing flow meters will experience when they are installed in pipelines having a pipe schedule that is different from standard. It is understood that meters are commonly laboratorycalibrated before they are installed and used in an industrial setting. However, unless the laboratory calibration was performed in the same pipe schedule as the pipeline in which the meters are to be installed in the field, significant errors may exist in the meter reading. This research demonstrates that some meter types must be laboratory-calibrated in the pipe schedule into which the meter will be installed or that a user must make a correction to obtain a more accurate flow reading.

This study evaluated pipe inside diameter effects on five types of 12 -in. DP meters. The types of meters chosen for this research were the classical Venturi meter, Halmi Venturi Tube (HVT), wedge meter, V-cone meter, and the X-meter. Each meter was tested for accuracy with 10 different pipe schedules installed upstream. The pipe schedules that were tested upstream of each of the meter types were 20, 30, STD, 40, 60, 80, 100, 120, 140, and 160 . The same Reynolds number range was tested for each test setup for comparison purposes.

\section{METER DESCRIPTIONS}

The flow rate for DP meters is calculated using the conservation of mass and the conservation of energy. When kinetic energy increases, the potential energy decreases to satisfy the principles of the conservation of energy. The change in energy is created by geometric restrictions placed inside the meter-a change in pipe diameter, which causes the water velocity to increase to satisfy the conservation of mass. This in turn results in a decrease in pressure at the constriction in the meter where the difference in fluid pressure is measured. It is important for the flow streamlines to be parallel to the pipe wall to ensure that the pressure tap measures a true piezometric reading. Upstream disturbances that cause eddies along the pipe wall can negatively affect the piezometric reading at the pressure-tap location.

A wide variety of geometric restrictions are used to generate the pressure drop in differential-producing meter types. The five types of meters in this research were donated by the manufacturers and had hydraulic shapes and dimensions as shown in Figure 1. All of the meters had a 0.6 beta ratio (the ratio of the throat diameter to the pipe diameter). It is important to note that while the fundamental principles are generally the same for the same type of DP meters, the scenarios used in this analysis are unique and cannot be applied to all meters. Different manufacturers may build the same type of meter differently. For example, the classical Venturi meter design specifies that the location of the upstream pressure tap can be between $0.5 \mathrm{D} \pm .05 \mathrm{D}$ (Miller 1996). This means the upstream tap may be anywhere between 5.4 and 6.6 in. upstream of the converging section on a 12 -in. meter. Additionally, the length of straight pipe before the converging section may be different if the meter was custom-made to fit in an existing pipeline. Upstream piping effects may also vary between the same types of meters as a result of the installation method, flange sizes, etc. Additionally, the beta ratio of the meter may vary within a meter type, and there are commonly slight differences in the same meter from the same manufacturer resulting from manufacturing tolerances and pressure-tap installation differences. For these reasons, the results in this analysis apply only to the specific meters in this scenario. However, the study does show to what degree each metering technology may be affected. This will enable a user to decide whether a currently installed meter may need to be recalibrated to get more accurate readings or whether the flow must be corrected.

\section{EXPERIMENTAL SETUP AND PROCEDURE}

The laboratory tests for this study were performed at the Utah Water Research Laboratory in Logan. All laboratory equipment used was calibrated and was traceable to the National Institute of Standards and Technology. More than $30 \mathrm{ft}$ of straight standard-wall carbon steel 12-in. pipe (12.000-in. ID) was installed upstream of the test setup to ensure the flow was near uniform as it approached the meter. A full set of carbon steel pipe spools was constructed, each spool being a different schedule with inside diameters shown in Table 1. Each test setup had one of the spools installed immediately upstream of the meter (Figure 2). The length of the spools was investigated using computational fluid dynamics (CFD) computer software before the testing to ensure the spool lengths were sufficient. Various upstream spool lengths were tested to see if the length affected the resulting discharge coefficient (the ratio of actual measured flow to theoretical measured flow). This exercise established the shortest acceptable spool lengths that could be used in the testing by determining the length at which the resulting discharge coefficients were affected beyond the uncertainties of the CFD solutions. The upstream spools used in the laboratory data were at least $5 \mathrm{ft}$ in length, which met or exceeded the acceptable length. It is worth noting that the CFD discharge coefficients matched the laboratory data to better than $0.5 \%$.

Immediately following the flow meter, approximately $15 \mathrm{ft}$ of straight standard wall pipe was always installed downstream of the meter. The discharge pipe directed flows to a 250,000-lbcapacity weight tank.

Each setup was tested at 10 Reynolds numbers in near-equal intervals between 70,000 and 1,300,000. The water temperature was measured, and the Reynolds number was calculated at the meter inlet for each test run. At the end of each test, the meter output was compared with the actual flow rate calculated from the values obtained from the weight tank. Most test series also included repeat data points to verify results or show repeatability. All results were displayed graphically for comparison. 


\section{FIGURE 1 Specifications of differential pressure meters used in this analysis}

\section{Classical Venturi Meter}

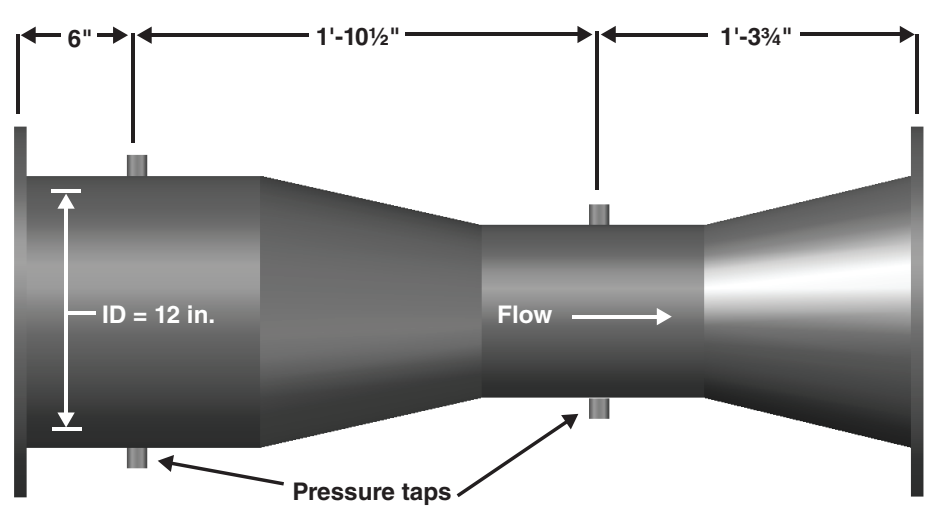

Specified accuracy: $\pm 0.25 \%$

$(200,000<\operatorname{Re}<6,000,000)$

Wedge Meter

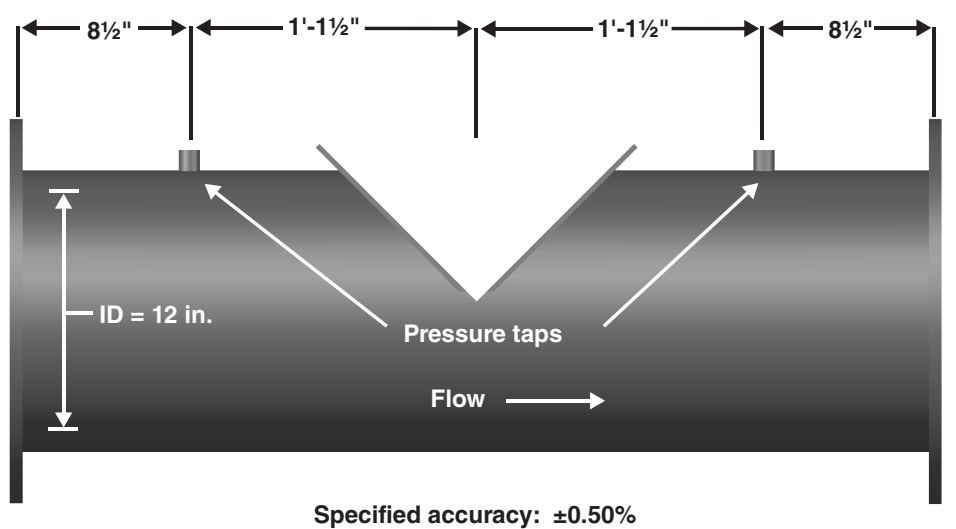

Halmi Venturi Tube

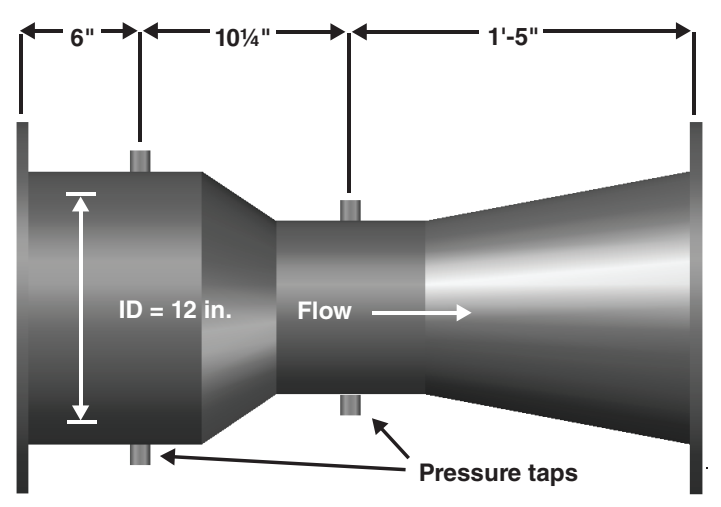

Specified accuracy: $\pm 0.25 \%$

$(\operatorname{Re}>75,000)$

V-cone Meter

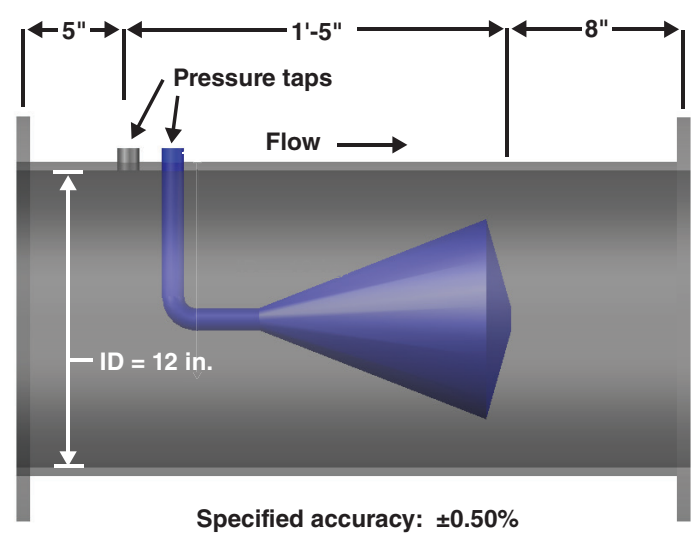

X-Meter

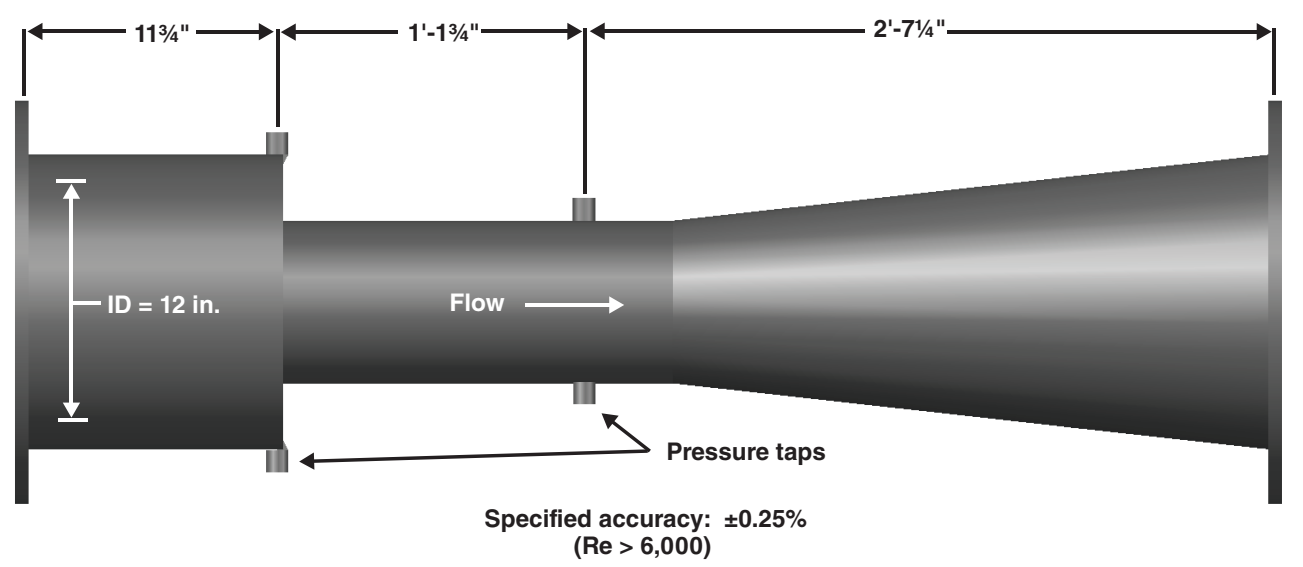

Sources: McCrometer Inc. 2014, PFS 2014

ID—inside diameter, Re-Reynolds number 
TABLE 1 Pipe schedule dimensions of 12-in. steel pipe

\begin{tabular}{|c|c|c|c|c|c|}
\hline Schedule & $\begin{array}{l}\text { Pipe Wall Thickness } \\
\text { in. }\end{array}$ & $\begin{array}{l}\text { Inside Diameter } \\
\text { in. }\end{array}$ & $\begin{array}{c}\text { Cross-Sectional Area } \\
\text { in. }^{2}\end{array}$ & $\begin{array}{c}\text { Offset Length } \\
\text { Referenced to STD } \\
\text { in. }{ }^{2}\end{array}$ & $\begin{array}{c}\text { Change in Area } \\
\text { Referenced to STD } \\
\%\end{array}$ \\
\hline 20 & 0.250 & 12.250 & 117.86 & $0.125 \mathrm{C}$ & 4.21 \\
\hline 30 & 0.330 & 12.090 & 114.80 & $0.045 \mathrm{C}$ & 1.51 \\
\hline STD & 0.375 & 12.000 & 113.10 & NA & NA \\
\hline 40 & 0.406 & 11.938 & 111.93 & $0.031 \mathrm{E}$ & -1.03 \\
\hline 60 & 0.562 & 11.626 & 106.16 & $0.187 \mathrm{E}$ & -6.14 \\
\hline 80 & 0.687 & 11.376 & 101.64 & $0.312 \mathrm{E}$ & -10.13 \\
\hline 100 & 0.843 & 11.064 & 96.14 & $0.468 \mathrm{E}$ & -14.99 \\
\hline 120 & 1.000 & 10.750 & 90.76 & $0.625 \mathrm{E}$ & -19.75 \\
\hline 140 & 1.125 & 10.500 & 86.59 & $0.750 \mathrm{E}$ & -23.44 \\
\hline 160 & 1.312 & 10.126 & 80.53 & $0.937 \mathrm{E}$ & -28.79 \\
\hline
\end{tabular}

C—contraction of the pipe radius as water enters the meter, E-expansion of the pipe radius as water enters the meter, NA—not applicable, STD—standard pipe wall thickness

An uncertainty analysis was completed on the laboratory data using procedures from the American Society of Mechanical Engineers' Performance Test Code 19.1-2005, Test Uncertainty, to determine uncertainty of the collected data on the discharge coefficient. The prescribed procedure examines each of the measured variables and enables bounds to be established to account for systematic (bias) and random measurement errors at the $95 \%$ confidence interval. The analysis of the test apparatus showed that the measured discharge coefficients had maximum uncertainties of $0.2 \%$ or less.

\section{RESULTS}

The results are shown graphically, and the expanded uncertainty is given for each meter type (ASME 2005). The values for the discharge coefficient $(C)$ were plotted on the basis of their percent difference from the value of $C$ with the meter in "ideal conditions" -installed in a pipeline of STD pipe schedule. In other words, the charts show how the meter readings differ from how a meter read after being calibrated in a STD-schedule pipeline. Thus, the differential values of $C$ when installed downstream of a STD-schedule pipe are represented by a straight line at $0.0 \%$ in the charts.

The values of $C$ in these ideal conditions were determined using linear interpolation of the results when the meter was installed in STD-schedule pipe. This was to ensure that the differences between $C$ values were being compared at equal Reynolds numbers. Values above the red STD line, which were caused by the effects of the pipe wall offset, indicate that the meter's coefficient was increased as a result of the offset. Conversely, values below the red line indicate the meter's coefficient was decreased. The shaded region in each chart represents the specified range of accuracy for the meter.

Classical Venturi meter effects. Results for the classical Venturi meter shown in Figure 3 were gathered with a maximum expanded uncertainty of $0.20 \%$ ranging between 0.11 and $0.20 \%$. A noticeable trend change occurred at the lowest tested
FIGURE 2 Experimental setup in the laboratory 12-in. test line

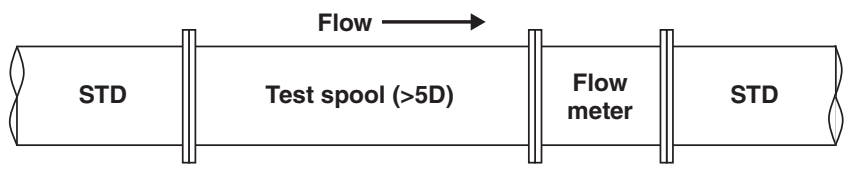

Sources: McCrometer Inc. 2014, PFS 2014

STD—standard

\section{FIGURE 3 Effects of pipe wall offsets on the classical} Venturi meter

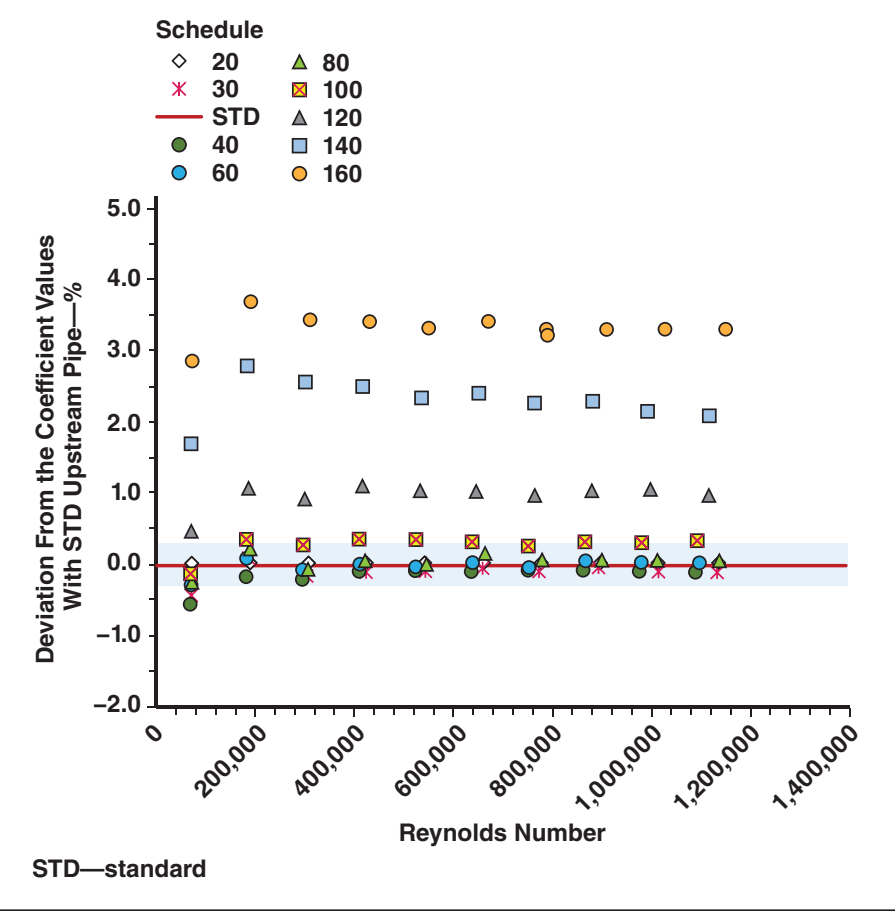


TABLE 2 Summary of results for the classical Venturi meter

\begin{tabular}{|c|c|c|c|c|c|c|c|c|c|c|}
\hline Pipe Schedule & 20 & 30 & STD & 40 & 60 & 80 & 100 & 120 & 140 & 160 \\
\hline Average coefficient & 0.9933 & 0.9937 & 0.9946 & 0.9932 & 0.9945 & 0.9951 & 0.9976 & 1.0046 & 1.0182 & 1.0283 \\
\hline $\begin{array}{l}\text { Deviation from average STD } \\
\text { coefficient- } \%\end{array}$ & -0.13 & -0.09 & NA & -0.14 & -0.01 & 0.05 & 0.30 & 1.01 & 2.37 & 3.39 \\
\hline Maximum coefficient value & 0.9947 & 0.9948 & 0.9959 & 0.9946 & 0.996 & 0.9965 & 0.9991 & 1.0059 & 1.0208 & 1.0291 \\
\hline Minimum coefficient value & 0.9911 & 0.9916 & 0.9891 & 0.9910 & 0.9924 & 0.9926 & 0.9959 & 1.0024 & 1.0168 & 1.0268 \\
\hline $\begin{array}{l}\text { Deviation of maximum from } \\
\text { average STD coefficient-\% }\end{array}$ & 0.01 & 0.02 & 0.13 & 0.00 & 0.14 & 0.19 & 0.45 & 1.14 & 2.63 & 3.47 \\
\hline $\begin{array}{l}\text { Deviation of minimum from } \\
\text { average STD coefficient-\% }\end{array}$ & -0.35 & -0.30 & -0.55 & -0.36 & -0.22 & -0.20 & 0.13 & 0.78 & 2.23 & 3.24 \\
\hline Standard deviation of coefficients & 0.0009 & 0.0009 & 0.0009 & 0.0013 & 0.0011 & 0.0011 & 0.0010 & 0.0011 & 0.0013 & 0.0008 \\
\hline
\end{tabular}

NA—not applicable, Re—Reynolds number, STD—standard pipe wall thickness

Table values are for $\operatorname{Re}>200,000$

Reynolds number for each offset. As with all Venturi meters, the discharge coefficient gets smaller as the Reynolds number decreases once the Reynolds number is lower than the meter's stable zone. This coincides with the meter's specifications in which the discharge coefficient holds constant at Reynolds numbers between 200,000 and 6,000,000.

The meter showed little to no effect from the sudden contractions and the smaller sudden expansions. The first sign of the coefficient being outside the specified accuracy band of $\pm 0.25 \%$, based on the laboratory calibrated constant $C$ value, occurred when pipe schedule 100 was installed upstream, where the coefficient increased by $0.34 \%$. The subsequent data of pipe wall offsets greater than 0.468 in. followed a pattern that shows that the coefficient increased as the pipe wall offset increased. The discharge coefficients increased from 0.26 to $3.59 \%$. Table 2 summarizes all of the data collected for the meter.

HVT effects. Results shown for the HVT in Figure 4 had a maximum expanded uncertainty of $0.20 \%$ and a range of $0.11-$ $0.20 \%$. The results immediately displayed an upward trend in several data sets at Reynolds numbers below 400,000. In this range, the meter was affected by negative upstream diameter offsets caused by the smaller pipe schedules installed upstream. The coefficient was reduced by as much as $1.0 \%$ in these conditions. Curiously, the data sets for schedules 40 and 60 also caused the coefficient to be reduced in this range even though they both have larger diameters than the ideal STD schedule (a sudden expansion of pipe radius). The HVT is reported to have a constant discharge coefficient for Reynolds numbers above 75,000. For this reason, the sloping trend reaching as far as 500,000 in some cases seems irregular.

With the exception of the aforementioned irregularities, the results were similar to those of the classical Venturi meter. At Reynolds numbers above 500,000, the meter showed little to no effect from the negative diameter changes and the smaller positive diameter changes. With pipe schedule 80 installed upstream, the error in flow measurement first began to drift outside the $\pm 0.25 \%$ accuracy band. The following data sets above schedule 80 follow the pattern of increased error from $0.26 \%$ to $3.89 \%$. Table 3 summarizes all of the data collected for the meter.
Wedge meter effects. Results for the wedge meter shown in Figure 5 had a maximum expanded uncertainty of $0.19 \%$ and a range of $0.10-0.19 \%$. The results show that the meter was not significantly affected by any diameter offsets upstream of the meter. At least, the effects from the offsets did not cause the meter to produce readings outside of its specified accuracy of $0.50 \%$. The reason for such resilience may be due to the locations of the pressure taps. The low-pressure tap is not located at the throat but further downstream. All other meters tested in this analysis had pressure taps at or very near the throat of the meter. More research is needed to prove this correlation. Table 4 summarizes all of the data collected for the meter.

\section{FIGURE 4 Effects of pipe wall offsets on the Halmi Venturi Tube}

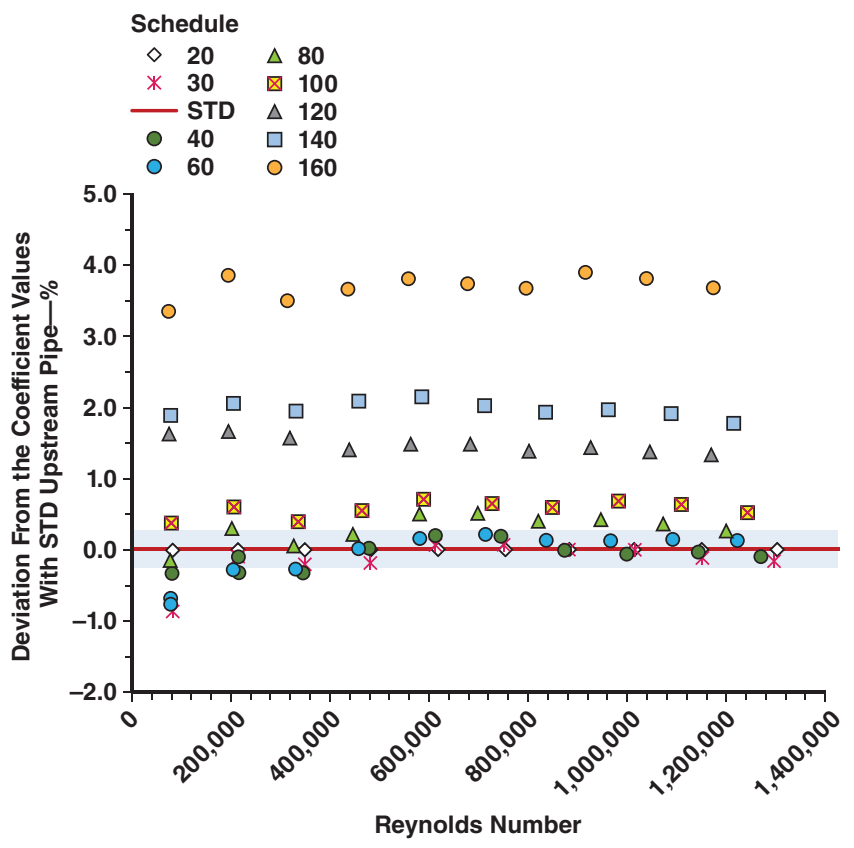

STD—standard 
TABLE 3 Summary of results for the Halmi Venturi Tube

\begin{tabular}{|c|c|c|c|c|c|c|c|c|c|c|}
\hline Pipe Schedule & 20 & 30 & STD & 40 & 60 & 80 & 100 & 120 & 140 & 160 \\
\hline Average coefficient & 0.9851 & 0.9854 & 0.9862 & 0.9857 & 0.9865 & 0.9894 & 0.9920 & 1.0006 & 1.0058 & 1.0233 \\
\hline $\begin{array}{l}\text { Deviation from average STD } \\
\text { coefficient- } \%\end{array}$ & -0.11 & -0.08 & NA & -0.05 & 0.03 & 0.32 & 0.59 & 1.46 & 1.99 & 3.76 \\
\hline Maximum coefficient value & 0.9867 & 0.9874 & 0.9888 & 0.9877 & 0.9881 & 0.9913 & 0.9943 & 1.0048 & 1.0088 & 1.0267 \\
\hline Minimum coefficient value & 0.9839 & 0.9839 & 0.9842 & 0.9836 & 0.9855 & 0.9880 & 0.9906 & 0.9981 & 1.0031 & 1.0213 \\
\hline $\begin{array}{l}\text { Deviation of maximum from } \\
\text { average STD coefficient-\% }\end{array}$ & 0.05 & 0.12 & 0.26 & 0.15 & 0.19 & 0.52 & 0.82 & 1.89 & 2.29 & 4.11 \\
\hline $\begin{array}{l}\text { Deviation of minimum from } \\
\text { average STD coefficient-\% }\end{array}$ & -0.23 & -0.23 & -0.20 & -0.26 & -0.07 & 0.18 & 0.45 & 1.21 & 1.71 & 3.56 \\
\hline Standard deviation of coefficients & 0.0008 & 0.0011 & 0.0018 & 0.0014 & 0.0008 & 0.0011 & 0.0012 & 0.0026 & 0.0022 & 0.0016 \\
\hline
\end{tabular}

NA—not applicable, Re—Reynolds number, STD—standard pipe wall thickness

Table values are for $\mathrm{Re}>75,000$

FIGURE 5 Effects of pipe wall offsets on the wedge meter

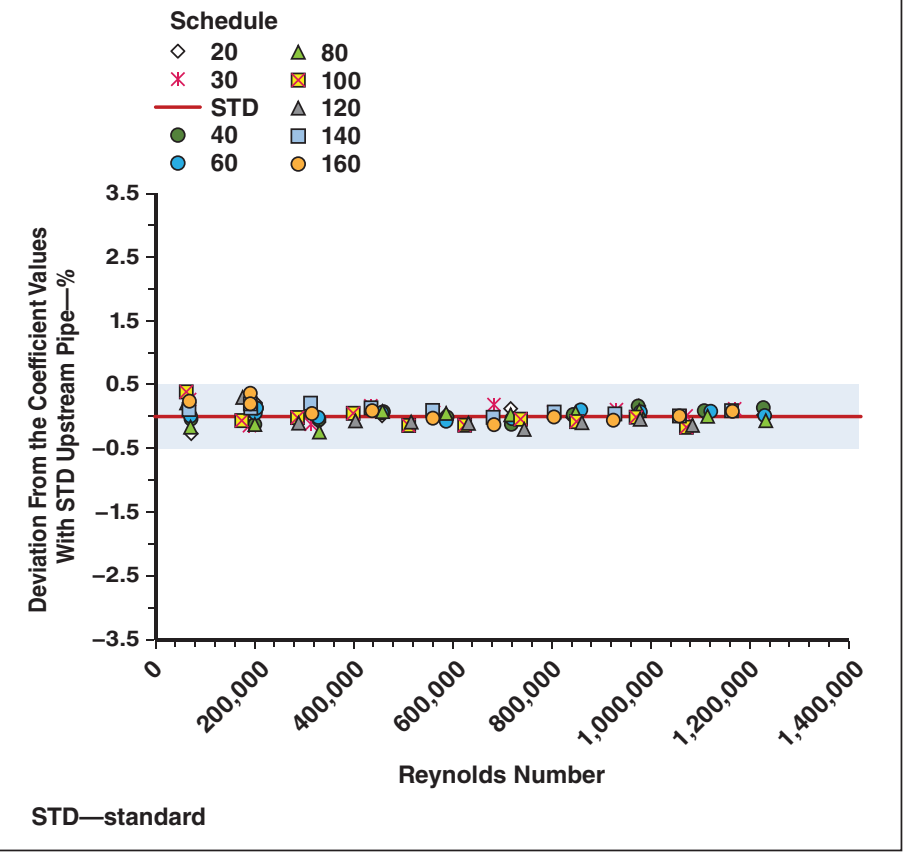

V-cone meter effects. Calculated uncertainty for the results of the $\mathrm{V}$-cone meter had a maximum expanded value of $0.21 \%$ and a range of $0.16-0.21 \%$. The results are shown in Figure 6 . The changes in the discharge coefficient were as much as $3.26 \%$ for the tested Reynolds numbers in this analysis. Each data set showed that the discharge coefficient increases as Reynolds number continues to increase beyond 500,000. It is possible that the error may continue to increase if the upward trend continues.

There did not appear to be any identifiable pattern from the data. For example, schedule 60 and schedule 140 caused nearly the same effect, but schedule 120 upstream caused a larger effect than schedule 140 upstream in most cases. Another obvious result shows the much larger effect from schedule 160 than all other pipe schedules. There were also repeatability issues when installed in a schedule 160 pipeline for subsequent data verification. This may have been the case with other pipe schedules, but there are not sufficient data to support this. The repeatability of other schedules was better than the schedule 160 , but there is some instability in the data. Table 5 summarizes all of the data collected for the meter.

X-meter effects. Results for the X-meter shown in Figure 7 were gathered with a maximum uncertainty of $0.20 \%$, ranging between 0.11 and $0.20 \%$. The meter showed signs of being

TABLE 4 Summary of results for the wedge meter

\begin{tabular}{|c|c|c|c|c|c|c|c|c|c|c|}
\hline Pipe Schedule & 20 & 30 & STD & 40 & 60 & 80 & 100 & 120 & 140 & 160 \\
\hline Average coefficient & 0.6845 & 0.6849 & 0.6844 & 0.6844 & 0.6846 & 0.6842 & 0.6842 & 0.6841 & 0.6849 & 0.6848 \\
\hline $\begin{array}{l}\text { Deviation from average STD } \\
\text { coefficient- } \%\end{array}$ & 0.01 & 0.07 & NA & 0.00 & 0.03 & -0.03 & -0.03 & -0.04 & 0.07 & 0.06 \\
\hline Maximum coefficient value & 0.6861 & 0.6862 & 0.6854 & 0.6861 & 0.6861 & 0.6858 & 0.6870 & 0.6858 & 0.6857 & 0.6860 \\
\hline Minimum coefficient value & 0.6825 & 0.6816 & 0.6824 & 0.6816 & 0.6828 & 0.6816 & 0.6824 & 0.6826 & 0.6834 & 0.6838 \\
\hline $\begin{array}{l}\text { Deviation of maximum from } \\
\text { average STD coefficient- } \%\end{array}$ & 0.25 & 0.26 & 0.15 & 0.25 & 0.25 & 0.20 & 0.38 & 0.20 & 0.19 & 0.23 \\
\hline $\begin{array}{l}\text { Deviation of minimum from } \\
\text { average STD coefficient-\% }\end{array}$ & -0.28 & -0.41 & -0.29 & -0.41 & -0.23 & -0.41 & -0.29 & -0.26 & -0.15 & -0.09 \\
\hline Standard deviation of coefficients & 0.0011 & 0.0015 & 0.0009 & 0.0013 & 0.0010 & 0.0014 & 0.0012 & 0.0009 & 0.0007 & 0.0007 \\
\hline
\end{tabular}

NA—not applicable, STD—standard pipe wall thickness 


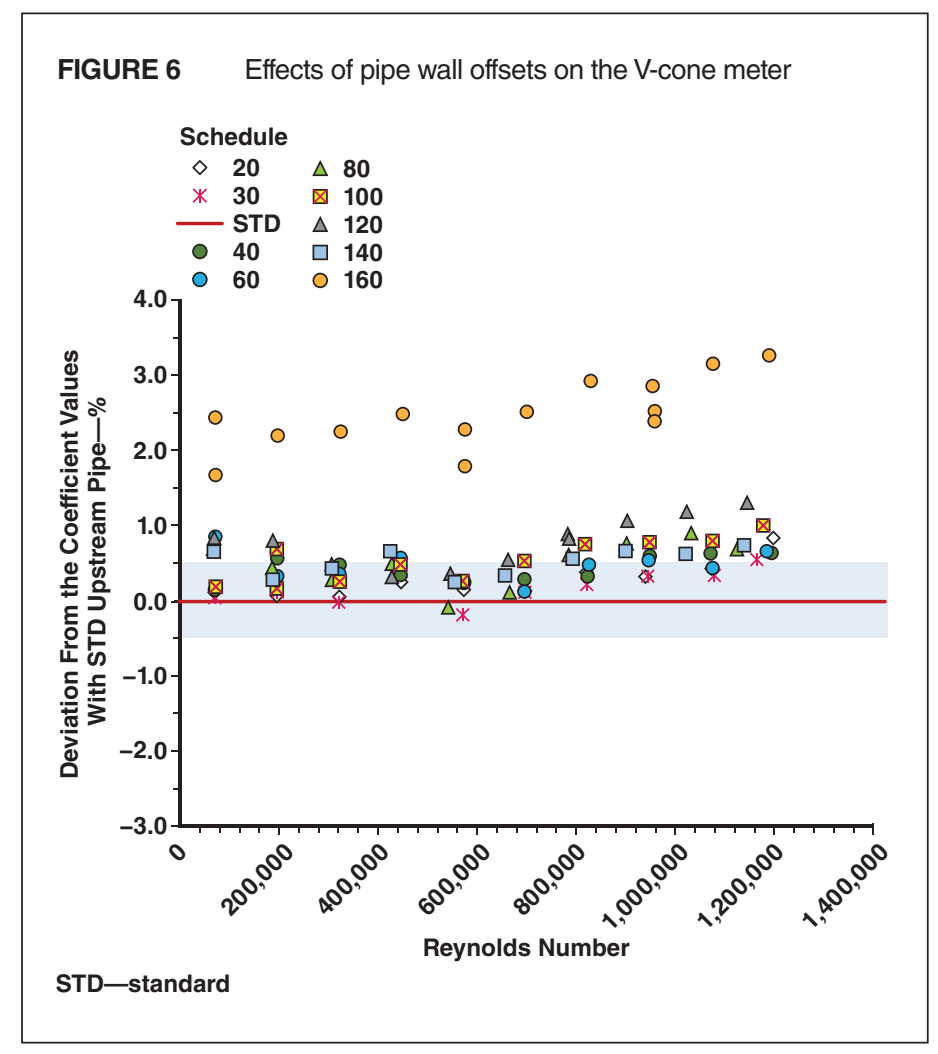

FIGURE 7 Effects of pipe wall offsets on the X-meter

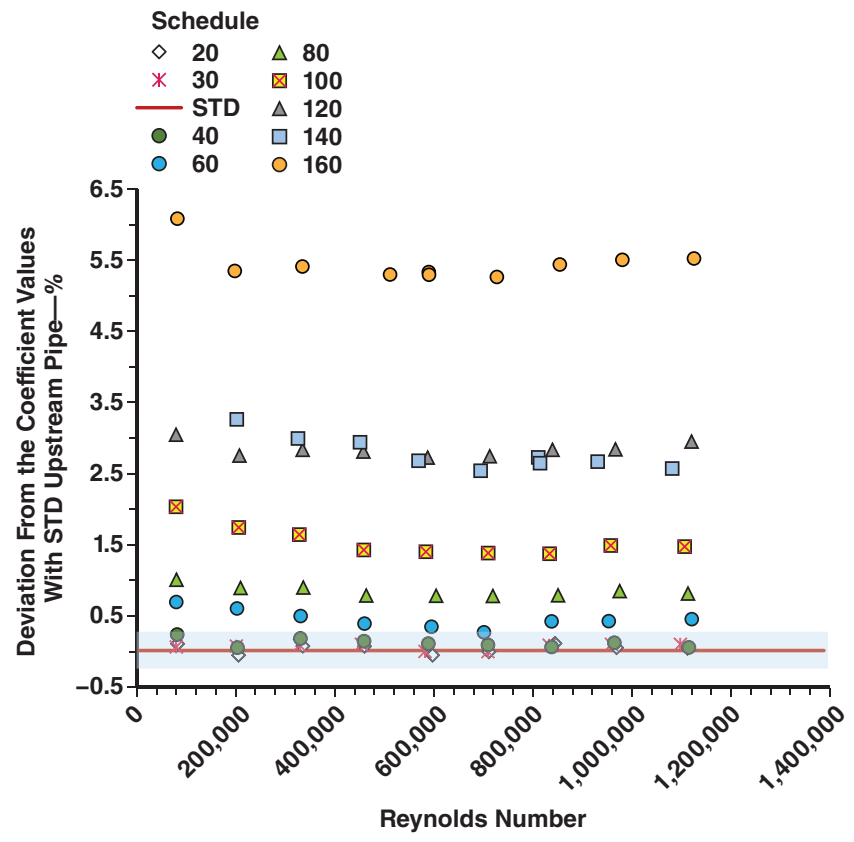

STD—standard

TABLE 5 Summary of results for the V-cone meter

\begin{tabular}{|c|c|c|c|c|c|c|c|c|c|c|}
\hline Pipe Schedule & 20 & 30 & STD & 40 & 60 & 80 & 100 & 120 & 140 & 160 \\
\hline Average coefficient & 0.8032 & 0.8025 & 0.8015 & 0.8044 & 0.8047 & 0.8048 & 0.8051 & 0.8071 & 0.8051 & 0.8207 \\
\hline $\begin{array}{l}\text { Deviation from average STD } \\
\text { coefficient- } \%\end{array}$ & 0.21 & 0.12 & NA & 0.36 & 0.40 & 0.41 & 0.45 & 0.70 & 0.45 & 2.40 \\
\hline Maximum coefficient value & 0.8083 & 0.8056 & 0.8047 & 0.8077 & 0.8103 & 0.8090 & 0.8094 & 0.8114 & 0.8087 & 0.8276 \\
\hline Minimum coefficient value & 0.8005 & 0.7997 & 0.7992 & 0.8017 & 0.8004 & 0.8008 & 0.8034 & 0.8031 & 0.8027 & 0.8155 \\
\hline $\begin{array}{l}\text { Deviation of maximum from } \\
\text { average STD coefficient—\% }\end{array}$ & 0.85 & 0.51 & 0.40 & 0.77 & 1.10 & 0.94 & 0.99 & 1.24 & 0.90 & 3.26 \\
\hline $\begin{array}{l}\text { Deviation of minimum from } \\
\text { average STD coefficient-\% }\end{array}$ & -0.12 & -0.22 & -0.29 & 0.02 & -0.14 & -0.09 & 0.24 & 0.20 & 0.15 & 1.75 \\
\hline Standard deviation of coefficients & 0.0020 & 0.0018 & 0.0019 & 0.0019 & 0.0025 & 0.0025 & 0.0017 & 0.0026 & 0.0017 & 0.0031 \\
\hline
\end{tabular}

NA—not applicable, STD—standard pipe wall thickness

TABLE 6 Summary of results for the X-meter

\begin{tabular}{|c|c|c|c|c|c|c|c|c|c|c|}
\hline Pipe Schedule & 20 & 30 & STD & 40 & 60 & 80 & 100 & 120 & 140 & 160 \\
\hline Average coefficient & 0.8147 & 0.8149 & 0.8144 & 0.8153 & 0.8181 & 0.8213 & 0.8271 & 0.8377 & 0.8384 & 0.8593 \\
\hline $\begin{array}{l}\text { Deviation from average STD } \\
\text { coefficient- } \%\end{array}$ & 0.04 & 0.06 & NA & 0.11 & 0.45 & 0.85 & 1.56 & 2.86 & 2.95 & 5.51 \\
\hline Maximum coefficient value & 0.8153 & 0.8155 & 0.8152 & 0.8159 & 0.8197 & 0.8222 & 0.8307 & 0.8390 & 0.8445 & 0.8640 \\
\hline Minimum coefficient value & 0.8141 & 0.8144 & 0.8139 & 0.8144 & 0.8173 & 0.8206 & 0.8255 & 0.8372 & 0.8351 & 0.8585 \\
\hline $\begin{array}{l}\text { Deviation of maximum from } \\
\text { average STD coefficient—\% }\end{array}$ & 0.11 & 0.14 & 0.10 & 0.18 & 0.65 & 0.96 & 2.00 & 3.02 & 3.70 & 6.09 \\
\hline $\begin{array}{l}\text { Deviation of minimum from } \\
\text { average STD coefficient-\% }\end{array}$ & -0.04 & 0.00 & -0.06 & 0.00 & 0.36 & 0.76 & 1.36 & 2.80 & 2.54 & 5.42 \\
\hline Standard deviation of coefficients & 0.0004 & 0.0003 & 0.0005 & 0.0006 & 0.0008 & 0.0005 & 0.0016 & 0.0005 & 0.0029 & 0.0016 \\
\hline
\end{tabular}

NA—not applicable, STD—standard pipe wall thickness 
affected when pipe schedules above 40 were installed upstream, in which case the results are outside the $\pm 0.25 \%$ accuracy band. The correction coefficient was increased by as much as $6.1 \%$ with schedule 160 installed upstream. There was also a noticeable trend in that most of the data sets showed that the effects were slightly higher at lower Reynolds numbers. Perhaps the most noticeable irregularity occurred with schedule 140 . For unknown reasons, the meter is more affected by schedule 120 rather than schedule 140 in some cases. Table 6 summarizes all of the data collected for the meter.

\section{CONCLUSION}

Standard-schedule DP flow meters being installed in pipes with schedules other than STD may affect the meter's ability to accurately measure the flow unless the meter was calibrated in pipe representative of the actual installation. These results were based on how the meter performed while installed in a pipeline of schedule other than STD after being previously calibrated in a STD-schedule pipeline. Note that the results of the analysis apply to the specific DP meters only in this research scenario. Meters of the same type may respond differently as a result of the method of installation into the pipeline and locations of the pressure taps in reference to the sudden change in diameter.

In most cases, the meters were resilient to negative-diameter offsets (sudden contractions) from the smaller pipe schedules; however, this study did not test as large a size of offsets that produce sudden contractions as the offsets that produce sudden expansions. Results showed that positive-diameter offsets (sudden expansions) can have considerable effects on flow metering. As expected, the greater the change in pipe area, the greater the effect in most cases. In these cases, the sudden expansion that the flow experiences as it enters the meter causes flow measurement error by as much as $6.1 \%$ depending on the DP meter type and the specific upstream pipe size. If meters in these conditions are not corrected, the fluid cannot be accurately measured.

The results of this study prove that most flow meters may need to be installed in piping that has the same pipe schedule as the meter itself. If a standard-wall classical Venturi meter that was calibrated in standard-wall pipe was then installed in a pipeline that contained 120-schedule steel pipe, flow deviation of as much as $1.0 \%$ would be expected. To quantify the costs of this error, consider a water wholesaler providing water to a city with a population of 50,000 people. If water is sold to the city at a rate of $\$ 1.50 / 1,000 \mathrm{gal}$ and the average water use per person was $100 \mathrm{gpd}$, the company could be losing up to $\$ 27,000 /$ year as a result of the $1.0 \%$ error. If the company was using a schedule 160 pipe resulting in a $3.4 \%$ error, it could be losing up to \$93,333/year. Continuing research on water meter accuracy will help increase understanding of how to more effectively manage a fluid system.

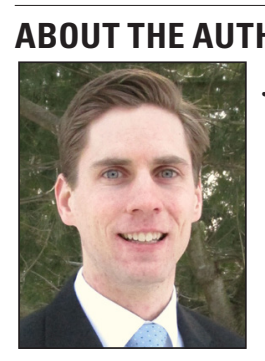

Jesse M. Pope (to whom correspondence may be addressed) is a staff engineer at Gannett Fleming, 207 Senate Ave., Camp Hill, PA 17011 USA; jpope@gfnet.com. He received his bachelor's and master's degrees in civil engineering from Utah State University in Logan. Pope has four years of experience in the water resources-related field, three years at the Utah Water Research Laboratory at Utah State University, and one year at Gannett Fleming. Steven L. Barfuss and Michael C. Johnson are research associate professors at Utah State University. Zachary B. Sharp is a research engineer at Utah State University.

\section{PEER REVIEW}

Date of submission: $11 / 04 / 14$

Date of acceptance: 02/20/15

\section{REFERENCES}

ASME (American Society of Mechanical Engineers), 2005. Test Uncertainty. ASME, New York.

Ifft, S.A. \& Mikkelsen, E.D., 1993. Pipe Elbow Effects on the V-Cone Flowmeter. Proc. ASME Fluids Engineering Conf., Washington.

McCrometer Inc., 2014. The V-Cone Flow Meter: A Superior DP Technology. www.mccrometer.com/library/pdf/24509-49.pdf (accessed May 20, 2014).

Miller, R.W., 1996. Flow Measurement Engineering Handbook. McGraw-Hill Cos. Inc., Boston.

Nayyar, M.L., 2000. Introduction to Piping. Piping Handbook. McGraw-Hill Cos. Inc., New York.

PFS (Primary Flow Signal Inc.), 2014. www.primaryflowsignal.com (accessed May 20, 2014).

Rapier, A.C., 1981. The Effect of Upstream Flow Conditions on Flow Meters. Proc. Intl. Conf. on Advances in Flow Measurement Techniques, Warwick, U.K. 